NBER WORKING PAPER SERIES

\title{
INFLATION INDICATORS AND INFLATION POLICY
}

Stephen G. Cecchetti

Working Paper No. 5161

\author{
NATIONAL BUREAU OF ECONOMIC RESEARCH \\ 1050 Massachusetts Avenue \\ Cambridge, MA 02138 \\ June 1995
}

This paper was prepared for the NBER's Tenth Annual Conference on Macroeconomics, March 10-11, 1995. I would like to thank Ben Bernanke, Michael Bryan, John Campbell, Bruce Hansen, Anil Kashyap, Don Kohn, Julio Rotemberg and Mark Watson for comments and suggestions. I am grateful to Michael Niemira and Roy Webb for providing their data, to Bruce Hansen for his programs, and to the National Science Foundation and the Federal Reserve Bank of Cleveland for financial and research support. This paper is part of NBER's research program in Monetary Economics. Any opinions expressed are those of the author and not those of the National Bureau of Economic Research.

(C) 1995 by Stephen G. Cecchetti. All rights reserved. Short sections of text, not to exceed two paragraphs, may be quoted without explicit permission provided that full credit, including $\odot$ notice, is given to the source. 


\title{
INFLATION INDICATORS AND \\ INFLATION POLICY
}

\begin{abstract}
In recent years, central bankers throughout the world have advocated that monetary policy shift toward inflation targeting. Recent actions in the U.S. serve to highlight the desire of the Federal Reserve to keep inflation both low and stable, while downplaying the likely output and employment consequences. But control of inflation requires both that one be able to forecast the future path of the price level and that one have estimates of what impact policy changes have on that path. Unfortunately, inflation is very difficult to forecast at even very near horizons. This is true because the relationship of candidate inflation indicators to inflation is neither very strong nor very stable. Beyond this, the relationship between monetary policy instruments, such as the Federal Funds Rate, and inflation also varies substantially over time and cannot be estimated precisely.

Construction of policy rules can take these difficulties into account. Several rules are examined, and they have the following interesting properties. First, since prices take time to respond to all types of impulses, the object of price stability implies raising the Federal Funds Rate immediately following a shock, rather than waiting for prices to rise before acting. Finally, comparison of the results of price level targeting with nominal income targeting suggests that the difficulties inherent in forecasting and controlling the former provide an argument for focusing on the latter.
\end{abstract}

Stephen G. Cecchetti

Department of Economics

Ohio State University

1945 N. High Street

Columbus, $\mathrm{OH}$ 43210-1172

and NBER 


\section{Introduction}

Since late 1979, the goal of monetary policy in the United States has progressively shifted toward the reduction of the level and variation of inflation. Recent policy actions serve to highlight the desire of the Federal Reserve to keep inflation both low and stable, while downplaying the likely output and employment consequences. The purpose of this paper is to evaluate the practicality and desirability of inflation targeting.

Any attempt to control the path of the aggregate price level has several critical aspects. First, policy makers must be able to forecast inflation. To run a proactive policy that controls prices, it is crucial that one be able to assess the future path of prices in the absence of any immediate policy action. In other words, given some candidate inflation indicator, the relationship between future inflation and the indicator must be known with some degree of accuracy. This leads to the first major question: Are there any useful indicators of future inflation? If, for example, we see the level of capacity utilization or the price of gold rise, can this be translated into a forecast for the aggregate price level?

Once prices are forecast to rise above a target path, the next step is to figure out what to do about it. But the extent of a response requires an accurate estimate of the impact of the policy instrument on inflation. Is it possible to estimate the effect of policy actions on prices? What is the precision of the estimates?

Finally, given these estimated response of prices to both exogenous shocks and policy, and an objective for the policy makers, it is possible to formulate policy rules. With these in hand, a series of practical questions can be addressed. First, how quickly and by how much should policy react to perceived upward price pressures? What are the quantitative benefits of price level targeting? By how much can the on the variance of inflation be reduced and at what cost, as measured by the increased variation of output? And finally, what are the consequences of shifting from price level to nominal income targeting?

The primary focus of this paper is on inflation. This can be justified by the fact that the reduced-form representation of a broad class of macroeconomic models 
depends only on inflation. A simple example can be constructed by starting with a standard staggered contract model in which nominal shocks have real effects that die out slowly. ${ }^{1}$ Assume that the monetary authority minimizes a loss function that depends on current and future deviations of output $\left(y_{t}\right)$ from its full-employment level $\left(y_{t}^{*}\right)$, as well as inflation $(\pi)$. This formulation ignores dynamic consistency problems, as it implicitly assumes that the loss is minimized at $y_{t}=y_{t}^{*}{ }^{2}$ Fixed nominal prices that change infrequently imply that output deviations are a distributed lag of unanticipated inflation, and so the loss function can be written in terms of actual inflation and expected inflation alone. It immediately follows that the optimal long run policy objective is be zero inflation. The dependence of policy on expectations only affects optimal disinflationary paths.

The remainder of this paper is divided into five sections. Section 2 discusses the difficulties facing policy makers in their attempt to control high- and mediumfrequency fluctuations in the aggregate price level. While evidence suggests that a $k$-percent rule may work well for controlling inflation in the long-run, at horizons of five to ten years or more, it may result in substantial swings in prices over horizons of two or three years. This leads to an examination of a more sophisticated approach in which one first tries to forecast the path of inflation, and then formulate a reaction function to control it. Sections 3 and 4 examine different aspects of the forecasting problem, while sections 5 and 6 study policy reaction functions. In section 3 two sets of results are presented. The first examines commercial forecasts from various sources. This is followed by an examination of the reduced form correlations between inflation and various candidate indicators. Section 4 examines structural changes in the relationship between inflation and the indicators. Section 5 looks closely at the relationship between monetary policy and inflation, and section 6 chooses a particular model to study optimal policy responses. Section 7 offers conclusions.

To anticipate the conclusions, I find that inflation is extremely difficult to forecast at horizons of even one quarter. One of the likely reasons for this is the fact that

\footnotetext{
${ }^{1}$ Examples of such models are numerous. See, for example, the one in Ball and Cecchetti (1988).

${ }^{2}$ Since price rigidity in staggered contract models usually results from monopolistic competition, social welfare will not in general be maximized at the general equilibrium level of output.
} 
the relationship between inflation and various candidate indicators exhibits rather frequent structural breaks. Beyond the forecasting problem, I also find that the relationship between inflation and policy is also difficult to estimate. Together, these lead to the final result: Shifting from price level to nominal income targeting yields a substantial gain in reduced real income stabilization, while resulting in only a small loss in increased aggregate price variability.

\section{The Nature of the Problem}

The apparent stability of long-run money demand functions implies that a Friedman-style $k$-percent rule for money growth could be used to reach either a long-run inflation or a long-run nominal GDP target. ${ }^{3}$ But recent experience teaches that monetary policy aimed at controlling short-run movements in nominal variables faces formidable problems.

Figure 1 plots the nominal GDP velocity of the monetary base, M1 and M2, from first quarter of 1959 through the third quarter of 1994. The data are standardized by removing a trend, subtracting the sample mean and dividing by the sample standard deviation. ${ }^{4}$ For the monetary base and M1, the trend has a break in $1986 .{ }^{5}$ These data suggest two things. First, the short-run instability in velocity has increased substantially over the past decade. Second, over the past two years, the velocity of M2 has increased dramatically, while that of the monetary base and M1 has declined. ${ }^{6}$ If one were to try to formulate a $k$-percent rule, the question would be $k$-percent of what?

\footnotetext{
${ }^{3}$ See, for example, Lucas (1988), Hallman, Porter and Small (1991) Stock and Watson (1993), and Feldstein and Stock (1994), among others.

${ }^{4}$ The standardization makes the reported values similar to coefficients from a regression of the detrended log of nominal GDP on the detrended log of money.

${ }^{5}$ The location of the break was determined using the Andrews (1993)/Quandt (1960) 'sup' test, robust to heteroskedasticity. For the monetary base, the break is estimated to occur in 1986:04, while for M1 the estimated break is in 1986:02. Obviously, real-time policy making would not have been able to take advantage of the shift that we can now estimate. This makes matters even worse than they appear here.

${ }^{6}$ The use of M2 encounters the additional problem of the changes in definition over time. Recently, Duca (1992) has suggested including the stock of bond mutual funds in a revised measure. A very skeptical way to view these modifications is to observe that $\mathrm{M} 2$ seems to be constructed so that its implied velocity is stationary about a constant mean of 1.65 .
} 
Figure 1: GDP Velocity of the Monetary Base, M1 and M2

Standardized, Quarterly, 1959Q1 to 1994Q3

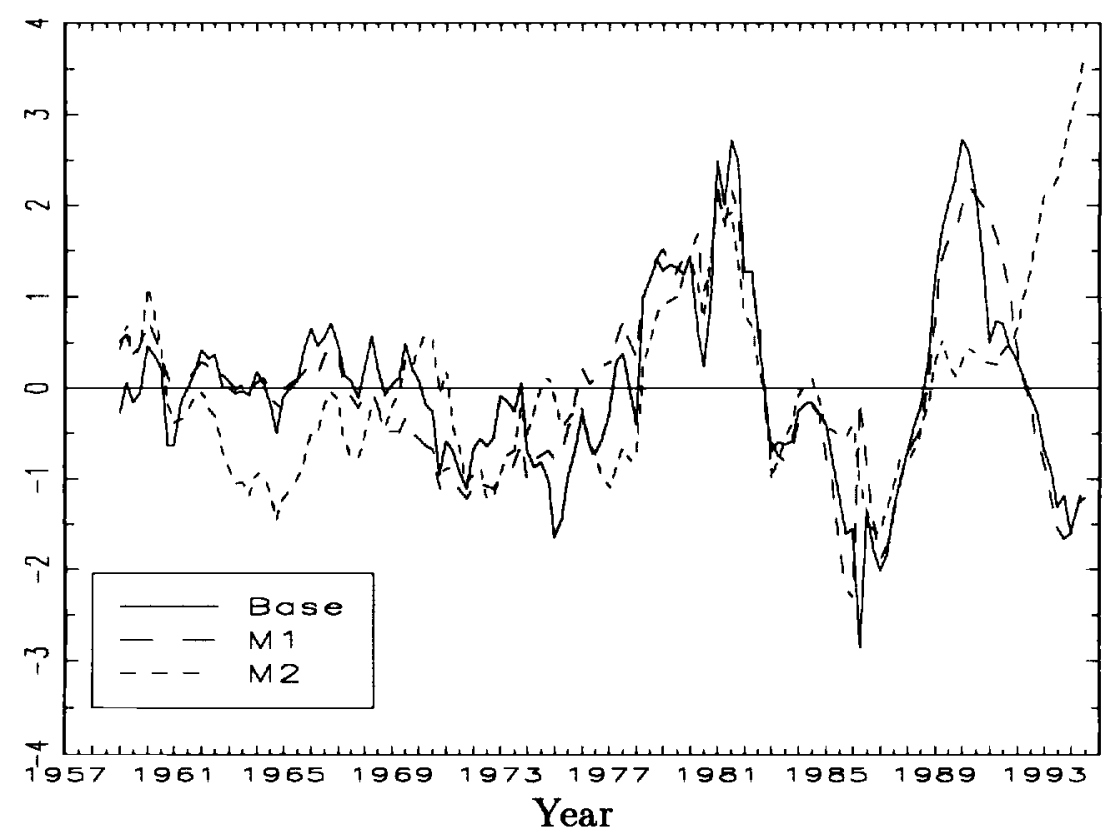

The implication of the recent instability in velocity is that it is hard to know how to run policy at high frequencies. To put it slightly differently, most economists would agree that if the monetary base grows at $10 \%$ rather than at $5 \%$, then inflation will be higher in the long run. But this tells us very little about how the monetary authority should act on a month-to-month basis. The natural response is to seek a more sophisticated feed-back rule that incorporates inflation, inflation indicators, and policy variables. That is the task addressed in the remainder of this paper.

\section{Forecasting Inflation}

The first step in formulating any policy aimed at reducing the level and variance of inflation, is to forecast the evolution of aggregate prices both with and without policy interventions. The next two sections examine our ability to forecast inflation, and the following sections report evidence on the impact of policy changes on prices. Since economic theory implies that different indicators should forecast inflation at 
different horizons, I present results for forecasts of inflation over future periods of varying length. ${ }^{7}$

In section 3.1, I examine the accuracy of contemporaneous inflation forecasts. Section 3.2 reports evidence on the simple correlation between indicators and inflation. Section 3.3 evaluates forecasts of inflation based on the indicators.

\subsection{Contemporaneous Forecasts}

There are several readily available sources for the history of commercial inflation forecasts. Table 1 reports the root-mean-square error of the quarterly and annual forecasts published by Data Resources Incorporated (DRI) and the consensus forecast from Blue Chip Economic Indicators. For comparison, the table also reports the results of using a simple random walk model for inflation. This 'naive' method takes current inflation as the forecast for all horizons.

Since forecasters report their expectations of the path for the price level into the future, it is possible to construct estimates of a term structure of expected future prices. Defining, $E_{t}\left[\pi_{t+l, t+k}\right]$ as the expectation at $t$ of inflation from $t+l$ to $t+k$ - the analog of a forward interest rate - it is possible to compute the accuracy of inflation forecasts for various horizons.

The results in the table suggest several conclusions. First, while always better than the benchmark naive forecasts, the commercial forecasts are very poor, even at a one-quarter horizon. For example, the root-mean-square error of DRI's onequarter ahead forecast $\left(E_{t}\left[\pi_{t, t+1}\right]\right)$ for 1982:01 to 1994:03 is 1.54 , implying a $70 \%$ confidence interval of three percentage points and a $90 \%$ confidence interval in excess of five percentage points! The Blue Chip consensus forecast is only marginally more accurate.

Second, the accuracy of the DRI forecasts declines as the horizon increases. This is particularly true for the early part of the sample, which includes the large oil price shocks of the middle and late 1970s. But even over the past dozen years, the inaccuracy of the forecasts increases with the horizon, rising by one-third as the

\footnotetext{
${ }^{7}$ Ball and Cecchetti (1990) make a similar point.
} 
Table 1: Root-Mean-Square Error of Published Forecasts

A. Data Resources

\begin{tabular}{|c|c|c|c|c|c|c|}
\hline \multirow[t]{2}{*}{$\begin{array}{c}\text { Horizon } \\
\text { (in Quarters) }\end{array}$} & \multicolumn{2}{|c|}{$\begin{array}{c}1970 \mathrm{Q} 2 \\
\text { to } 1994 \mathrm{Q} 3\end{array}$} & \multicolumn{2}{|c|}{$\begin{array}{c}1970 \mathrm{Q} 2 \\
\text { to } 1981 \mathrm{Q} 4\end{array}$} & \multicolumn{2}{|c|}{$\begin{array}{c}1982 \mathrm{Q} 1 \\
\text { to } 1994 \mathrm{Q} 3\end{array}$} \\
\hline & Actual & Naive & Actual & Naive & Actual & Naive \\
\hline$E_{t}\left[\pi_{t, t+1}\right]$ & 1.67 & 1.98 & 1.80 & 2.09 & 1.54 & 1.88 \\
\hline$E_{t}\left[\pi_{t+1, t+2}\right]$ & 2.30 & 2.53 & 2.77 & 2.80 & 1.75 & 2.26 \\
\hline$E_{t}\left[\pi_{t+2, t+3}\right]$ & 2.52 & 2.49 & 3.07 & 2.87 & 1.86 & 2.08 \\
\hline$E_{t}\left[\pi_{t+3, t+4}\right]$ & 2.80 & 3.01 & 3.52 & 3.54 & 1.86 & 2.39 \\
\hline$E_{t}\left[\pi_{t+4, t+5}\right]$ & 3.13 & 3.39 & 4.03 & 4.20 & 1.86 & 2.36 \\
\hline$E_{t}\left[\pi_{t+5, t+6}\right]$ & 3.26 & 3.52 & 4.20 & 4.56 & 1.92 & 2.00 \\
\hline$E_{t}\left[\pi_{t+6, t+7}\right]$ & 3.48 & 3.87 & 4.57 & 5.05 & 1.77 & 2.07 \\
\hline$E_{t}\left[\pi_{t+7, t+8}\right]$ & 3.86 & 4.26 & 5.03 & 5.49 & 1.98 & 2.36 \\
\hline$E_{t}\left[\pi_{t+8, t+9}\right]$ & 3.64 & 4.28 & 4.87 & 5.66 & 1.96 & 2.42 \\
\hline$E_{t}\left[\pi_{t+9, t+10}\right]$ & 3.43 & 4.14 & 4.84 & 5.78 & 2.00 & 2.51 \\
\hline$E_{t}\left[\pi_{t+10, t+11}\right]$ & 3.46 & 4.03 & 5.05 & 5.92 & 2.14 & 2.47 \\
\hline$E_{t}\left[\pi_{t+11, t+12}\right]$ & 3.67 & 4.47 & 5.74 & 7.17 & 2.03 & 2.24 \\
\hline $\begin{array}{c}\text { Mean Inflation } \\
\text { St. Dev. }\end{array}$ & \multicolumn{2}{|c|}{$\begin{array}{c}5.54 \\
10.50 \\
\end{array}$} & \multicolumn{2}{|c|}{$\begin{array}{c}7.66 \\
10.76\end{array}$} & \multicolumn{2}{|c|}{3.63} \\
\hline \multirow[t]{2}{*}{$\begin{array}{c}\text { Horizon } \\
\text { (in Years) }\end{array}$} & \multicolumn{2}{|c|}{$\begin{array}{c}1970 \mathrm{Q} 2 \\
\text { to } 1994 \mathrm{Q} 3 \\
\end{array}$} & \multicolumn{2}{|c|}{$\begin{array}{c}1970 \mathrm{Q} 2 \\
\text { to } 1981 \mathrm{Q} 4 \\
\end{array}$} & \multicolumn{2}{|c|}{$\begin{array}{c}1982 \mathrm{Q} 1 \\
\text { to } 1994 \mathrm{Q} 3\end{array}$} \\
\hline & Actual & Naive & Actual & Naive & Actual & Naive \\
\hline$E_{t}\left[\pi_{t, t+4}\right]$ & 1.79 & 2.13 & 2.32 & 2.43 & 1.06 & 1.79 \\
\hline$E_{t}\left[\pi_{t+4, t+8}\right]$ & 3.09 & 3.54 & 4.09 & 4.57 & 1.46 & 1.95 \\
\hline$E_{t}\left[\pi_{t+8, t+12}\right]$ & 3.48 & 4.13 & 5.65 & 6.61 & 1.61 & 2.06 \\
\hline
\end{tabular}

B. Blue Chip

\begin{tabular}{||c|cc||}
\hline \hline Horizon & \multicolumn{2}{|c||}{$1985 \mathrm{Q} 1$} \\
(in Quarters) & \multicolumn{2}{|c||}{ to 1994 Q3 } \\
\cline { 2 - 3 }$E_{t}\left[\pi_{t, t+1}\right]$ & Actual & Naive \\
\cline { 2 - 3 }$E_{t}\left[\pi_{t+1, t+2}\right]$ & 1.20 & 1.66 \\
$E_{t}\left[\pi_{t+2, t+3}\right]$ & 1.56 & 1.96 \\
$E_{t}\left[\pi_{t+3, t+4}\right]$ & 1.69 & 1.97 \\
$E_{t}\left[\pi_{t+4, t+5}\right]$ & 1.76 & 2.26 \\
\hline Mean Inflation & \multicolumn{2}{|c|}{3.64} \\
St. Dev. & \multicolumn{2}{|c|}{2.69} \\
\hline \hline Horizon & \multicolumn{2}{|c|}{$1985 \mathrm{Q} 1$} \\
(in Years) & to 1994 Q3 \\
\cline { 2 - 3 } & Actual & Naive \\
\cline { 2 - 3 }$E_{t}\left[\pi_{t, t+4}\right]$ & 1.02 & 1.65 \\
\hline \hline
\end{tabular}

Root-mean-square errors of 'Actual' forecasts are computed from published information. Root-mean-square errors of 'Naive' forecasts are computed assuming inflation is a random walk. 
horizon increases from one to ten quarters.

The table reports results for one-year forecasts, out up to three years. The results do show that the RMSE of the forecast one year ahead is quite a bit smaller than that for the forecast one quarter ahead. This suggests that forecasters might get the general trend in inflation roughly correct, but the high frequency movements that are reversed. Nevertheless, the forecasts still seem very inaccurate, implying $90 \%$ confidence intervals for one-year-ahead inflation of more than three percentage points.

\subsection{Correlation of Inflation with Candidate Indicators}

The next step is to examine how well different candidate indicators are correlated with inflation. To do this, I estimate the following simple regression:

$$
\pi_{t+l, t+k}=a(L) \pi_{t-1}+b(L) x_{t-1}+\epsilon_{t}(l, k)
$$

where $\pi_{t+l, t+k}$ is inflation from $t+l$ to $t+k, \pi_{t-1}$ is inflation from $t-2$ to $t-1, x$ is a candidate indicator, $a(L)$ and $b(L)$ are lag polynomials of order six, and $\epsilon_{t}$ is a stationary moving average error of order $(k-1)$ with i.n.i.d. innovations. ${ }^{8}$

Following the work of Neimira and Klein (1994), Webb and Rowe (1994), and others, the $x$ 's were chosen to include several commodity price indices, the price of gold, the price of oil, monetary aggregates, interest rates, interest rate spreads, a wage index, the trade-weighted exchange rate, a weekly hours index, the employment population ratio, capacity utilization, and unemployment. ${ }^{9}$ For the monthly sample beginning in January 1967, the set includes seventeen candidate variables. ${ }^{10}$

Table 2 reports results from estimating (1) for three horizons - one year ahead

\footnotetext{
${ }^{8}$ The order of the lag polynomial was chosen to enable estimation in the following section. Where they could be computed, results were shown to be equivalent to those using twelve lags.

${ }^{9}$ It is worth noting that there is a vast literature on forecasting inflation turning points. This work employs techniques that are similar to that used in general business cycle forecasting, and so is a bit removed from the work here. See Webb and Rowe (1994), and the citations therein.

${ }^{10}$ Inflation is measured using the All Items CPI-U with rental equivalence. From 1967 to 1982, this is the experimental ' $\mathrm{CPI}-\mathrm{U}$ X1'. All of the results are robust to using the weighted-median CPI described in Bryan and Cecchetti (1994).
} 
$(k=12, l=0)$, one to two years ahead $(k=24, l=12)$, and three to four years ahead $(k=48, l=36)$ - over two sample periods, 1967:01 to 1994:07 and 1982:01 to 1994:07. The numbers in the table are the p-values for the Wald form of the test that all of the elements of $b(L)$ are zero simultaneously, computed using a covariance matrix that is robust to heteroskedasticity and serial correlation. ${ }^{11}$

For the most part, both real variables, such as unemployment and capacity utilization, and material prices, such as the two spot price indices and the prices of gold or oil, are correlated with inflation at horizons of one or two years, but not at horizons of three to four years. The same is not true for the National Association of Purchasing Managers Diffusion index, the average hourly earnings index, the Weekly hours index, and the employment-population ratio. Increasing the horizon to five years does not change the results.

It is worth examining the case of capacity utilization in more detail. In addition to computing the simple test for all of the $b$ ' equally zero simultaneously, it is possible to calculate the sum of the coefficients - $b(1) .{ }^{12}$ Interestingly, an increase in capacity utilization is correlated with an increase in inflation at horizons of up to three years. For example, the t-ratio of $b(1)$ in the $(k=24, l=12)$ case is +6.97 . But after that, at horizons of three and four years, $b(1)$ is negative - for $(k=48, l=36)$ it is -1.98 .

The results for the different sample periods are dramatically different. For the more recent 1982 to 1994 period, very few variables help forecast inflation at a oneyear horizon, but most seem to be useful at longer horizons. This is likely the result of the relatively small amount of independent information used in the longer horizon estimates.

The main conclusion to be drawn from these simple correlations is that the different indicators provide information about inflation at different horizons, and that the information has changed over time. ${ }^{13}$

\footnotetext{
${ }^{11}$ The covariance matrix of the estimated coefficients is calculated using Newey and West (1987), with lags equal to $1.33 * k$.

${ }^{12}$ There are a number of well-known pitfalls associated with the interpretation of $b(1)$. Unless the sample includes periods in which capacity utilization movements are sustained for a number of months, then the sum of the coefficients is not a meaningful thing to compute. See Fisher and Seater (1993) for a discussion of related issues.

${ }^{13} \mathrm{~A}$ similar result emerges from a more complex (and computationally intensive) exercise of es-
} 
Table 2: Correlation of Inflation with Various Indicators

\begin{tabular}{|c|c|c|c|c|}
\hline Indicator & 3 Mor & $1 \mathrm{Yr}$ & 1 to $2 \mathrm{Yr}$ & 3 to $4 \mathrm{Yr}$ \\
\hline \multicolumn{5}{|c|}{ Sample 1967:01 to $1994: 07$} \\
\hline J. of Comm. Indus. Mater. & 0.01 & 0.00 & 0.01 & 0.99 \\
\hline NAPM Spot Index & 0.00 & 0.00 & 0.00 & 0.86 \\
\hline NAPM Diffusion Index & 0.00 & 0.00 & 0.02 & 0.02 \\
\hline Price of Gold, London fix & 0.34 & 0.00 & 0.00 & 0.97 \\
\hline Price of Oil, Brent North Crude & 0.06 & 0.11 & 0.68 & 0.74 \\
\hline Average Hourly Earnings & 0.03 & 0.19 & 0.18 & 0.02 \\
\hline Exchange Rate & 0.20 & 0.24 & 0.26 & 0.34 \\
\hline Monetary Base & 0.29 & 0.25 & 0.66 & 0.81 \\
\hline M1 & 0.72 & 0.72 & 0.90 & 0.47 \\
\hline M2 & 0.43 & 0.08 & 0.02 & 0.58 \\
\hline Federal Funds Rate $\left(r^{f f}\right)$ & 0.00 & 0.00 & 0.00 & 0.01 \\
\hline $10 \mathrm{Yr}$ Bond $-r^{f f}$ & 0.00 & 0.05 & 0.01 & 0.27 \\
\hline Commercial Paper $-r^{f f}$ & 0.00 & 0.01 & 0.00 & 0.02 \\
\hline Weekly Hours Index & 0.01 & 0.02 & 0.00 & 0.02 \\
\hline Capacity Utilization & 0.00 & 0.00 & 0.00 & 0.90 \\
\hline Unemployment Rate & 0.03 & 0.00 & 0.00 & 0.81 \\
\hline Employment Population Ratio & 0.05 & 0.01 & 0.00 & 0.00 \\
\hline \multicolumn{5}{|c|}{$\begin{array}{c}\text { Sample 1982:01 to 1994:07 } \\
\end{array}$} \\
\hline J. of Comm. Indus. Mater. & 0.25 & 0.04 & 0.01 & 0.00 \\
\hline NAPM Spot Index & 0.07 & 0.11 & 0.06 & 0.00 \\
\hline NAPM Diffusion Index & 0.09 & 0.00 & 0.02 & 0.00 \\
\hline Price of Gold, London fix & 0.33 & 0.61 & 0.75 & 0.01 \\
\hline Price of Oil, Brent North Crude & 0.75 & 0.61 & 0.64 & 0.00 \\
\hline Average Hourly Earnings & 0.85 & 0.64 & 0.02 & 0.02 \\
\hline Exchange Rate & 0.96 & 0.86 & 0.80 & 0.47 \\
\hline Monetary Base & 0.80 & 0.34 & 0.98 & 0.00 \\
\hline M1 & 0.61 & 0.12 & 0.47 & 0.00 \\
\hline M2 & 0.38 & 0.00 & 0.66 & 0.00 \\
\hline Federal Funds Rate $\left(r^{f f}\right)$ & 0.03 & 0.00 & 0.89 & 0.00 \\
\hline 10 Yr Bond $-r^{f f}$ & 0.00 & 0.00 & 0.00 & 0.00 \\
\hline Commercial Paper $-r^{f f}$ & 0.07 & 0.56 & 0.09 & 0.00 \\
\hline Weekly Hours Index & 0.35 & 0.69 & 0.76 & 0.00 \\
\hline Capacity Utilization & 0.20 & 0.03 & 0.20 & 0.00 \\
\hline Unemployment Rate & 0.00 & 0.00 & 0.18 & 0.00 \\
\hline Employment Population Ratio & 0.28 & 0.05 & 0.70 & 0.00 \\
\hline
\end{tabular}




\subsection{Inflation Indicators and Inflation Forecasting}

The simple regressions of the previous section may not be representative of the actual ability of an indicator to forecast inflation. Within-sample statistics suffer from over-fitting problems. These can be addressed by constructing out-of-sample forecasts. I do this with a series of rolling regressions, in which an equation is estimated over a sample of fixed length, a one-period-ahead forecast is computed, the next observation in the sample is added and the last one dropped, and the process is repeated. Table 3 reports the results from two such experiments. The first uses a ten year sample beginning in 1967 , while the second employs a five-year window with data beginning in 1982. Again, the calculations are done for forecasts at various horizons. In addition to reporting the simple root-mean-square error of the forecasts, the table includes the rank correlation between the RMSE of a model and its Bayes Information Criteria (BIC) for the initial sample. ${ }^{14}$

The first row in each panel of the table reports the results of forecasting inflation using inflation alone. As is clear, additional variables can easily worsen the forecast. For example, when forecasting inflation from three to four years into the future, the addition of eleven of the seventeen indicators raises the root-mean-square-forecast error. Adding any of the price measures worsens the forecasts. Only the wage index, M1, the Federal Funds Rate, the Commercial Paper spread, the weekly hours index, and the employment/population ratio improve the forecast. At shorter horizons things are a bit better. Regardless of the sample period, only eight of the seventeen variables worsen forecasts over the next year.

A number of other interesting results emerge from this exercise. First, with the

timating and ranking all of the possible models with all subsets of seventeen indicator variables. Using the Bayes Information Criterion (see footnote 14 below) as a ranking criterion, substantially different models are chosen for different horizons and sample periods. For example, using the entire sample period and a horizon of twelve months, the preferred model includes the NAPM Spot Index, the Price of Oil, M2, Capacity Utilization and Unemployment Rate. But for a thirty-six month horizon and the full 1967:01 to 1994:07 sample the 'best' model includes only M2 and the Federal Funds Rate.

${ }^{14}$ For a model with $p$ parameters estimated over a sample of length $T$ the BIC is defined as $\left[\ln \sigma_{\epsilon}^{2}+\frac{p}{T} \ln T\right]$, where $\sigma_{\epsilon}^{2}$ is the error variance. These statistics, which are similar to an adjusted $R^{2}$, are only suggestive, as their relevance has been established only for the case in which the regression error process is not serially correlated. 
Table 3: Root-Mean-Square Errors One-Step Ahead Rolling Forecasts

\begin{tabular}{||l|c|c|c|c||}
\hline \hline \multicolumn{5}{|c||}{ Sample 1967:01 to 1994:07, 10 Year Window } \\
\hline Indicator & 3 Mon & 1 Yr & 1 to 2 Yr & 3 to 4 Yr \\
\hline CPI only & 2.14 & 1.70 & 2.39 & 2.50 \\
J. of Comm. Indus. Mater. & 2.15 & 1.64 & 2.38 & 2.63 \\
NAPM Spot Index & 2.07 & 1.63 & 2.36 & 2.60 \\
NAPM Diffusion Index & 2.09 & 1.48 & 2.19 & 2.54 \\
Price of Gold, London fix & 2.24 & 1.68 & 2.35 & 2.73 \\
Price of Oil, Brent North Crude & 2.35 & 1.73 & 2.43 & 2.61 \\
Average Hourly Earnings & 2.09 & 1.71 & 2.43 & 2.44 \\
Exchange Rate & 2.24 & 1.71 & 2.27 & 2.63 \\
Monetary Base & 2.14 & 1.64 & 2.27 & 2.55 \\
M1 & 2.25 & 1.73 & 2.45 & 2.48 \\
M2 & 2.22 & 1.79 & 2.47 & 2.67 \\
Federal Funds Rate( $\left.{ }^{f f}\right)$ & 2.27 & 1.77 & 2.05 & 1.90 \\
10 Yr Bond - $r^{\text {ff }}$ & 2.13 & 1.77 & 2.22 & 2.53 \\
Commercial Paper - $r^{f f}$ & 2.27 & 1.87 & 2.25 & 2.19 \\
Weekly Hours Index & 2.28 & 1.81 & 2.34 & 2.08 \\
Capacity Utilization & 2.14 & 1.52 & 2.24 & 2.83 \\
Unemployment Rate & 2.20 & 1.65 & 2.33 & 2.89 \\
Employment Population Ratio & 2.27 & 1.75 & 2.52 & 2.17 \\
\hline Rank Correlation of Initial Sample & -0.13 & 0.15 & 0.01 & 0.00 \\
BIC with RMSE & $(0.25)$ & $(0.25)$ & $(0.25)$ & $(0.25)$ \\
\hline \hline
\end{tabular}

\begin{tabular}{||l|c|c|c||}
\hline \hline \multicolumn{3}{|c||}{ 1982:01 to 1994:07, 5 Year Window } \\
\hline Indicator & 3 Mon & 1 Yr & 1 to 2 Yr \\
\hline CPI only & 1.54 & 1.28 & 1.43 \\
J. of Comm. Indus. Mater. & 1.60 & 1.45 & 1.30 \\
NAPM Spot Index & 1.72 & 1.45 & 1.39 \\
NAPM Diffusion Index & 1.70 & 1.42 & 1.49 \\
Price of Gold, London fix & 1.60 & 1.35 & 1.68 \\
Price of Oil, Brent North Crude & 1.95 & 1.50 & 1.72 \\
Average Hourly Earnings & 1.65 & 1.32 & 1.47 \\
Exchange Rate & 1.64 & 1.38 & 1.56 \\
Monetary Base & 1.68 & 1.14 & 1.61 \\
M1 & 1.54 & 1.08 & 1.58 \\
M2 & 1.55 & 1.16 & 1.32 \\
Federal Funds Rate $\left(r^{f f}\right)$ & 1.43 & 1.16 & 0.97 \\
10 Yr Bond - $r^{f f}$ & 1.43 & 0.90 & 1.30 \\
Commercial Paper $-r^{f f}$ & 1.61 & 1.35 & 1.48 \\
Weekly Hours Index & 1.59 & 1.17 & 1.22 \\
Capacity Utilization & 1.56 & 1.06 & 1.03 \\
Unemployment Rate & 1.45 & 0.80 & 1.07 \\
Employment Population Ratio & 1.28 & 0.77 & 1.12 \\
\hline Rank Correlation of Initial Sample & -0.10 & -0.03 & -0.22 \\
BIC with RMSE & $(0.25)$ & $(0.25)$ & $(0.24)$ \\
\hline \hline
\end{tabular}


exception of the three month horizon, this forecasting method compares favorably with the commercial available forecasts. But both are rather poor. Second, there is virtually no correlation between the ranking of the models by their forecast error RMSEs and their initial sample BIC's! $!^{15}$ Whether a model fits well in-sample tells us virtually nothing about its out-of-sample forecasting ability.

\section{Structural Breaks in the Inflation Process}

A natural conclusion to draw from the simple examination of the previous section is that the inflation process is changing over time. If these changes were gradual, then the rolling-sample procedures used in Section 3.3 might take care of the problem. But there is a good reason to believe that this will not be the case, and that the correlation between inflation and candidate indicators, the $x$ 's, will experience structural breaks. ${ }^{16}$

It is straightforward to see why this might happen. For the sake of discussion, assume that inflation is actually determined by the following 'structural' model:

$$
\pi_{t+1}=\alpha(L) r_{t}+\beta(L) X_{t}+\omega_{t+1}
$$

where, $r_{t}$ is 'policy,' and $X_{t}$ is a vector of determinants.

Next, write the policy reaction function as

$$
r_{t}=\gamma(L) X_{t}+\nu_{t}
$$

The role of the policy maker is to choose $\gamma(L)$, the reaction of $r_{t}$ to observed $X$ 's. Since $\gamma(L)$ can contain zeros, a policy regime need not react to every element in $X$.

\footnotetext{
${ }^{15}$ Miyao (1994, Chapter 3) reports a similar result for the relationship between real and monetary variables.

${ }^{16} \mathrm{~A}$ number of researchers have modeled changes in the inflation process. Caskey (1985) examines a linear model with Bayesian learning, while Evans and Wachtel (1993) investigate the possibility that inflation shifts between a stationary and unit root process.
} 
Now consider the reduced-form regression:

$$
\pi_{t+1}=R(L) X_{t}+\eta_{t}
$$

Since

$$
R(L)=\alpha(L) \gamma(L)+\beta(L)
$$

changes in policy, which are changes in $\gamma(L)$, will change the correlation between $X$ and $\pi$. In effect, the reduced-form inflation regressions subsume the monetary policy reaction function (3), and so a change in the monetary authorities policy rule which may be a change in the relative weight placed on various indicators - will cause changes in (4). ${ }^{17}$

Note also that if the policy objective is to minimize $\operatorname{Var}\left(\pi_{t}\right)$, then the optimal policy reaction function sets $\gamma(L)=-\alpha(L)^{-1} \beta(L)$ and so inflation is uncorrelated with its determinants. This is one version of a point made by Kareken and Solow (1963) and Sims (1982), and more recently by Woodford (1994).

This suggests looking for structural breaks in the relationship between inflation and indicators. Shifts should occur near the times at which monetary policy procedures changed. To do this, I examine regressions of inflation one-year ahead on candidate indicators -- equation (1) in Section 3.2 with $(l=0, k=12)-$ using a combination of Andrews and Ploberger (1994) exponential Wald tests for structural stability, and Andrews (1993)/Quandt (1960) tests.

The Andrews/Quandt test is the maximum value of the statistic associated with the test that a break occurred at each point in the sample. It provides an estimate of the break date itself. The Andrews and Ploberger test is an exponentially weighted average of the statistics assuming a break at each date in the sample, and tests for structural stability generally. Calculation of the second of these requires the choice of a truncation parameter $(\tau)$ denoting the proportion of the beginning and of the end of the sample not to be used in the computations. The results reported below choose $\tau$ to be the same proportion at the beginning and end of the sample, and equal to the number of right-hand-side variable plus twelve months, divided by the sample size.

\footnotetext{
${ }^{17}$ This is yet another form of the Lucas (1976) critique.
} 
As it is currently worked out, the econometric theory that forms the basis for these tests presumes that there is a single structural break in the relation under study. Since there is every reason to believe that the monetary policy process has changed more than once over the 1967 to 1994 sample, one would like a procedure that allos for more than one break date. To do this, I have employed these tests in a recursive manner. If the Andrews/Ploberger test rejects structural stability at the five percent level, then the sample is split at the date implied by the Andrews/Quandt test. ${ }^{18}$ Assuming that enough data remain - in the results reported here, the sample must be a minimum of three years long - the tests are run again.

The results of this sequential procedure are reported in Table 4 . The tests are robust to heteroskedasticity and serial correlation. ${ }^{19}$ The full sample extends from January 1967 to July 1994. In addition to estimated break dates, the table reports the p-values for the Wald test that all of the elements of $b(L)$ are zero simultaneously for a sample beginning the month following the previous break (or the beginning of the full sample) until the next break (or the end of the full sample). Since the right-hand-side variable in the regressions is inflation over the proceeding twelve months, these dates can be interpreted as suggesting a change in the inflation process sometime during the year following the reported date.

To understand how the table is constructed, take the example of the model using M2. The results suggest that the relationship between inflation and M2 changed four times over the sample, with estimated breaks in April 1972, October 1978, August 1983 and September 1989. This leaves five stable sub-samples, the three between these four dates, the one from the beginning of the sample in January 1967 to the date of the first break in 1972, and the final one from September 1989 to the end of the sample in July 1994. The results from the Wald tests show that the coefficients on M2 in the inflation regression are significantly different from zero at standard levels of statistical significance in all but one of the sub-periods. For the sample from 1983:08 to 1989:09, the p-value for the test of the coefficients on M2 is only 0.08. For the

\footnotetext{
${ }^{18}$ The p-values for these tests are constructed using the techniques described in Hansen (1995).

${ }^{19}$ All test statistics are robust to both heteroskedasticity and serial correlation, using the Newey and West (1987) formulation with $m=15$. The serial correlation correction is required, since the estimated regressions make use of overlapping data.
} 
Table 4: Estimated Timing of Structural Breaks in the Inflation Process 
remainder of the sub-periods, the estimated p-value is below 0.05 .

The results show a number of interesting features. First, all of these relationships are highly unstable, with a minimum of three estimated breaks for a series. ${ }^{20}$ In addition, the break dates show a distinct pattern. Nearly all of the bivariate relationships shows shifts in early- to mid-1972, between 1979 and 1982 and around 1989. A number of series also exhibit evidence of breaks in 1976. The four real variables show breaks in the mid-1980s as well.

Several of these shifts are as expected, since they are around the times of the three important changes in Federal Reserve operating procedures that occurred during sample. These were: (1) the 1972 shift from free reserve to federal funds rate targeting; ${ }^{21}$ (2) the 1979 move to a nonborrowed reserves operating procedure; and (3) the 1982 change back to federal funds rate targeting. ${ }^{22}$

The $\mathbf{p}$-values for the test $H_{o}: \mathbf{b}=0$, where $\mathbf{b}$ is the vector of coefficients in $b(L)$, also suggest some interesting conclusions. In only four cases - the NAPM Diffusion Index, the T-Bond spread, Capacity Utilization and Weekly Hours - are the p-values always near zero, implying that the indicators are always correlated with inflation over the next year, but that the correlation changes. For the remainder, the hypothesis that the correlation is zero is not rejected for at least one sub-period. ${ }^{23}$ Policy makers are not just changing their emphasis on particular indicators, during some periods they appear to be ignoring some of them completely.

One criticism of the results in Table 4 is that they consider only bivariate relationships. There might be some multivariate inflation equation that is stable over the twenty-seven and one-half year sample period. But examination of multivariate models suggests that the problem persists. To establish this, I began by performing a model selection exercise in which I considered all 65,536 possible models comprising all of the subsets of the seventeen indicators variables, each entered with six lags.

\footnotetext{
${ }^{20}$ These results are consistent with those of Stock and Watson (1994), who find widespread instability in bivariate macroeconomic time series relationships.

${ }^{21}$ This may also represent the imposition of the Nixon wage-price controls, which began in August 1971 , and the end of the Bretton Woods system shortly thereafter.

${ }^{22}$ See Strongin (1992) for a full description of these changes.

${ }^{23}$ Both the signs and magnitude of the coefficients in these regressions change as well. For eleven of the seventeen indicators, there is a change in the sign of the sum of the response of inflation between sub-samples. For the remaining six, coefficients often change by factors of five to ten.
} 
Ranking the models by their BIC, the 'best' model for inflation one-year ahead included the NAPM Spot Index, the Price of Oil, M2, Capacity Utilization and the Unemployment Rate. The recursive structural break procedure in this specification reveals three break dates: 1974:12, 1981:01 and 1987:04. These clearly conform to the pattern in Table $6 .^{24}$

Taken together, the results of the last two sections lead one to draw some fairly strong conclusions. First, inflation is extremely difficult to forecast with any accuracy. Second, different indicators provide information about future inflation over different horizons. And most importantly, shifts in the reduced for correlations occur frequently and at times that suggest they are the result of changes in Federal Reserve operating procedures. ${ }^{25}$

\section{The Relationship Between Policy and Inflation}

The real-time conduct of monetary policy requires quantitative knowledge of the link between instruments and targets. For example, if the federal funds rate moves, then when and by how much does the price level change? An estimate of the impulse response of prices to policy innovations is one answer to this question.

There is now a vast literature on identification of monetary policy disturbances. ${ }^{26}$ One currently popular technique is to examine a reduced form vector autoregression that includes measures of the log of output, the log of aggregate prices, the $\log$ of commodity prices and a monetary policy indicator, such as the Federal Funds rate or the log of nonborrowed reserves. The structural form of such a model can be written as

$$
\left[\begin{array}{l}
p_{t} \\
p_{t}^{c} \\
y_{t} \\
r_{t}
\end{array}\right]=A(L)\left[\begin{array}{c}
\epsilon_{p t} \\
\epsilon_{\mathrm{ct}} \\
\epsilon_{y t} \\
u_{t}
\end{array}\right]
$$

\footnotetext{
${ }^{24}$ The same result holds for the second and third specifications ranked by their full-sample BIC.

${ }^{25}$ It is interesting to note that the same set of tests applied to the seventeen bivariate relationship of Federal Funds with the indicators (and inflation itself) show no evidence of structural breaks in any of the cases.

${ }^{26}$ See Sims (1992) and Christiano, Eichenbaum and Evans (1994a, 1994b) for discussions.
} 
where $p_{t}, p_{t}^{c}$, and $y_{t}$ are the logs of the aggregate price level, commodity prices and output, respectively, $r_{t}$ is the policy indicator, $A(L)$ is a $4 \times 4$ matrix of lag polynomials in the lag operator $L$, the $\epsilon^{\prime} s$ are the 'exogenous' shocks, and $u$ is the policy innovation.

For the purposes of the exercise here, all that is needed is to identify the response of the four variables in the system to the policy innovation $u_{t}$. This limited identification is achieved by assuming that no other variables respond to monetary policy shocks contemporaneously. That is, the first three rows of the fourth column of $A(0)$ are each zero.

Given the results of the previous section, it seems foolish to presume that the response of the aggregate price level to innovations in the Federal Funds Rate would be invariant over the past quarter century. In fact, the estimates in Table 4 suggest that there have been four changes in the bivariate relationship between inflation and the Federal Funds rate - 1972:10, 1978:12, 1983:04 and 1989:07. The average length of a regime is under six years.

In an attempt to take account of structural instability, I have computed the response of prices and output to policy innovations from a model estimated using a fixed ten-year rolling sample. I measure prices by the CPI, commodity prices by the Journal of Commerce index, output as industrial production, and monetary policy using the Federal Funds Rate. ${ }^{27}$

Figure 2 plots the impulse response for a one percentage point federal funds rate shock for horizons of one, two and three years. The result of each regression is plotted on the final date of the sample used. For example, the responses plotted on December 1984 are computed from a VAR estimated over the ten years of data beginning with January 1975. The top panel plots results for the log of prices, and the bottom panel plots those for the log of industrial production. The results are roughly as expected. One year following a monetary tightening, prices are usually predicted to fall, but by only a small amount. By comparison, following a policy action, output is forecast to fall substantially. After three years, output will have recovered, while prices will have

\footnotetext{
${ }^{27}$ The general character of the results are robust to changes in the commodity price index, use of an interpolated estimate of monthly GDP, and the substitution of the log of nonborrowed reserves for the Federal Funds Rate.
} 
Figure 2:

Response of Prices to Unit Federal Funds Rate Shock

12. 24 and 36 Month Horizon

Rolling Regressions using 10 year Samples

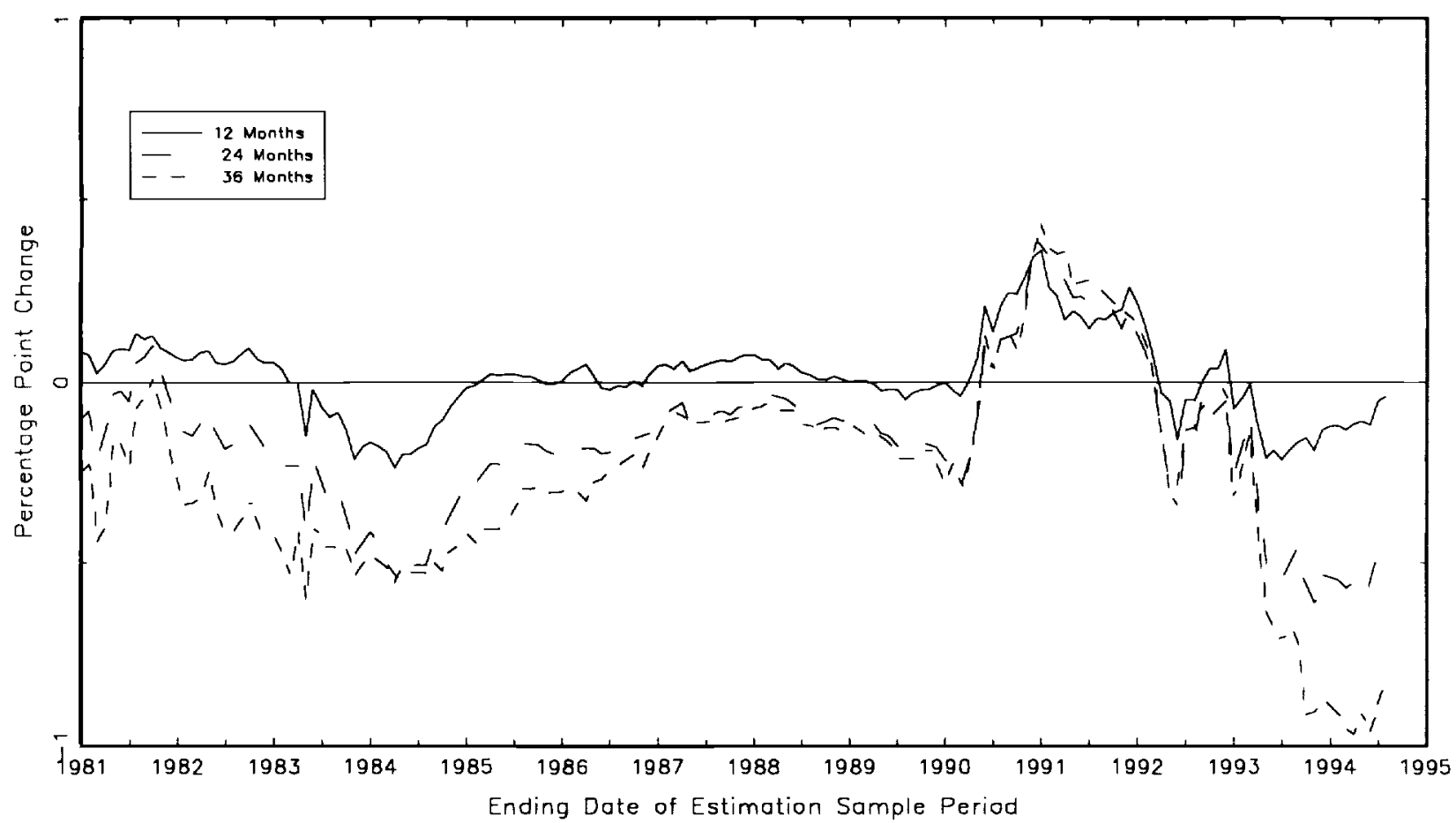

Response of Output to Unit Federal Funds Rate Shock

12, 24 and 36 Month Horizon

Rolling Regressions using 10 year Samples

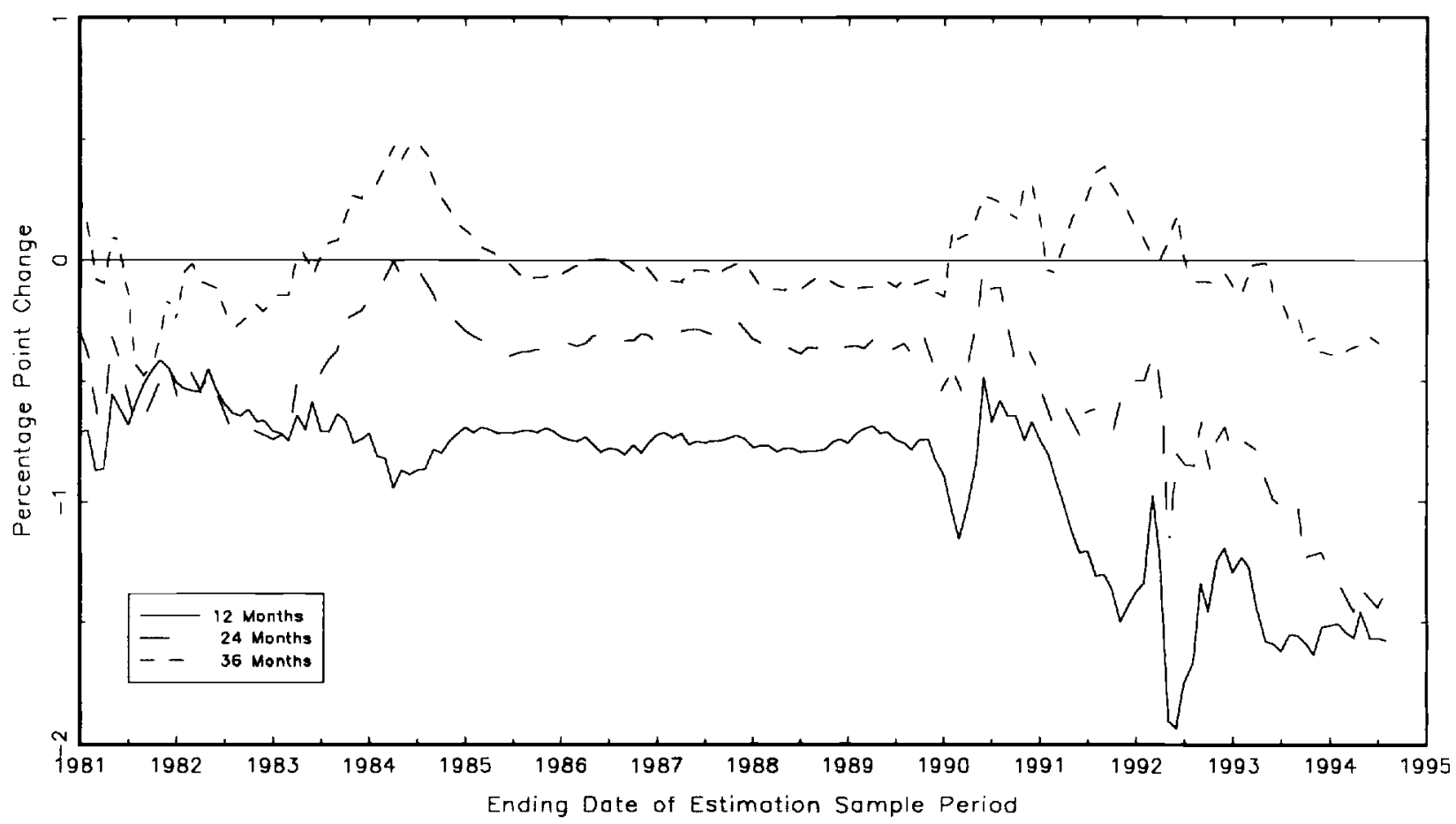


fallen substantially.

While the results in Figure 2 imply that the relationship between interest rates and inflation is unstable, they strongly suggest that monetary policy tightening leads to price declines. But these are only point estimates. The estimates of $A(L)$ have a sampling distribution that can be constructed using the delta method. Figure 3 reports the impulse responses for prices, with two-standard-deviation bands computed using the delta method. To aid in comparison, the vertical scale is the same in all three panels of the figure. The results are quite striking. In only a few isolated cases is it possible to reject (at conventional levels of statistical significance) that policy has no impact on prices.

\section{Policy Rules}

The results thus far highlight the importance of taking account of the dramatic imprecision both in the inflation forecasts and in the estimates of the impact of policy on prices in formulating policy rules. ${ }^{28}$ The goal of this section is to compute several policy rules that take account of some of these sources of our ignorance. Once constructed, these rules provide help in answering some immediately relevant questions. First, once policy makers sense that an exogenous shock has hit the economy, what is the time-profile of the optimal response? Second, and more importantly, given the apparent practical limits, is price level targeting really desirable or might nominal income targeting be more sensible? And finally, has recent policy followed a path that is close to the one implied by one of the rules?

Formulation of a policy rule proceeds in several clear steps. First, an identified model must be specified. This allows estimation of the response of variable of interest, i.e. prices and output, to both exogenous shocks and policy innovations. Next, it is necessary to assume a form for the loss function of the policy maker. Minimization of the loss function then yields appropriate responses to the shocks.

Application of this procedure begins with the VAR described in the previous sec-

\footnotetext{
${ }^{28}$ See Brainard (1967) for an early discussion of the importance of accounting for uncertainty in the formation of policy rules.
} 
Figure 3:

Respanse of Prices to Unit Federal Funds Rate Shock, 12 Month Harizon

Rolling Regrossions using 10 year Samales

(with Two Standord Doviation Bands)

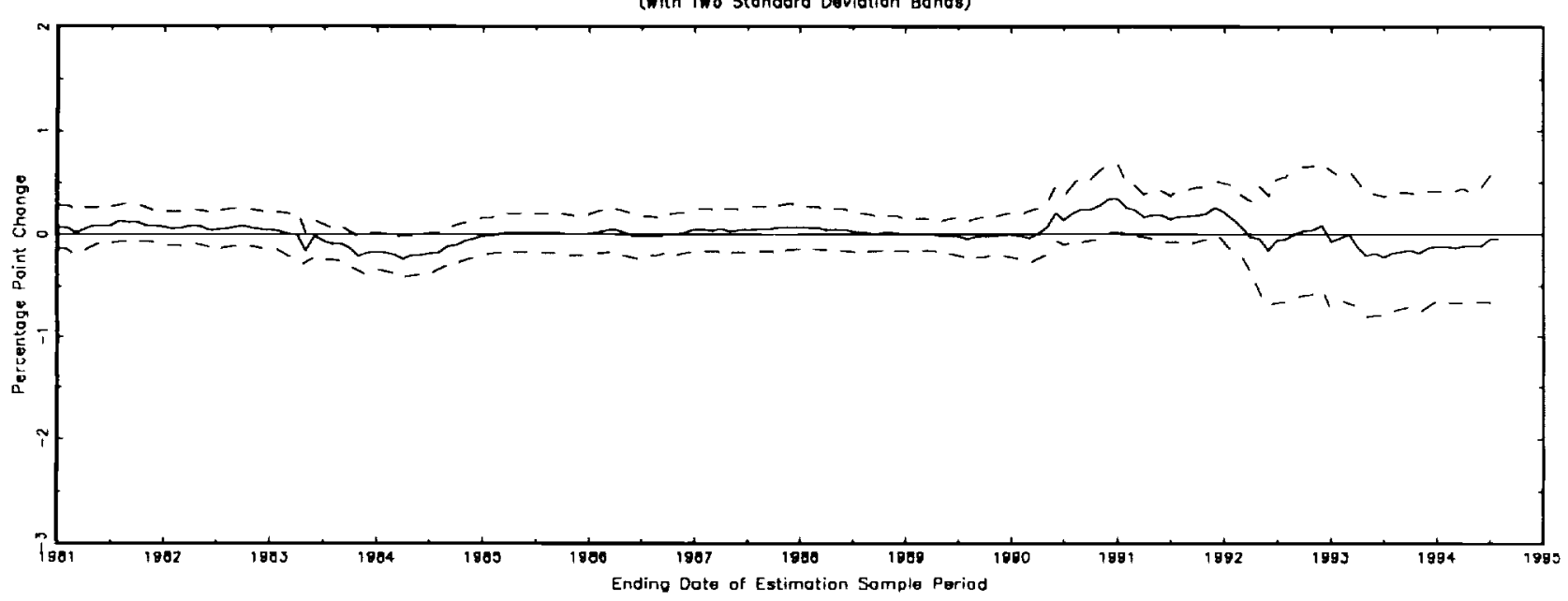

Response of Prices to Unit Federal Funds Rote Shock, 24 Month Horizon

Rolling Regreseions using 10 yeor Samples

(with Two Standard Deviation Bands)

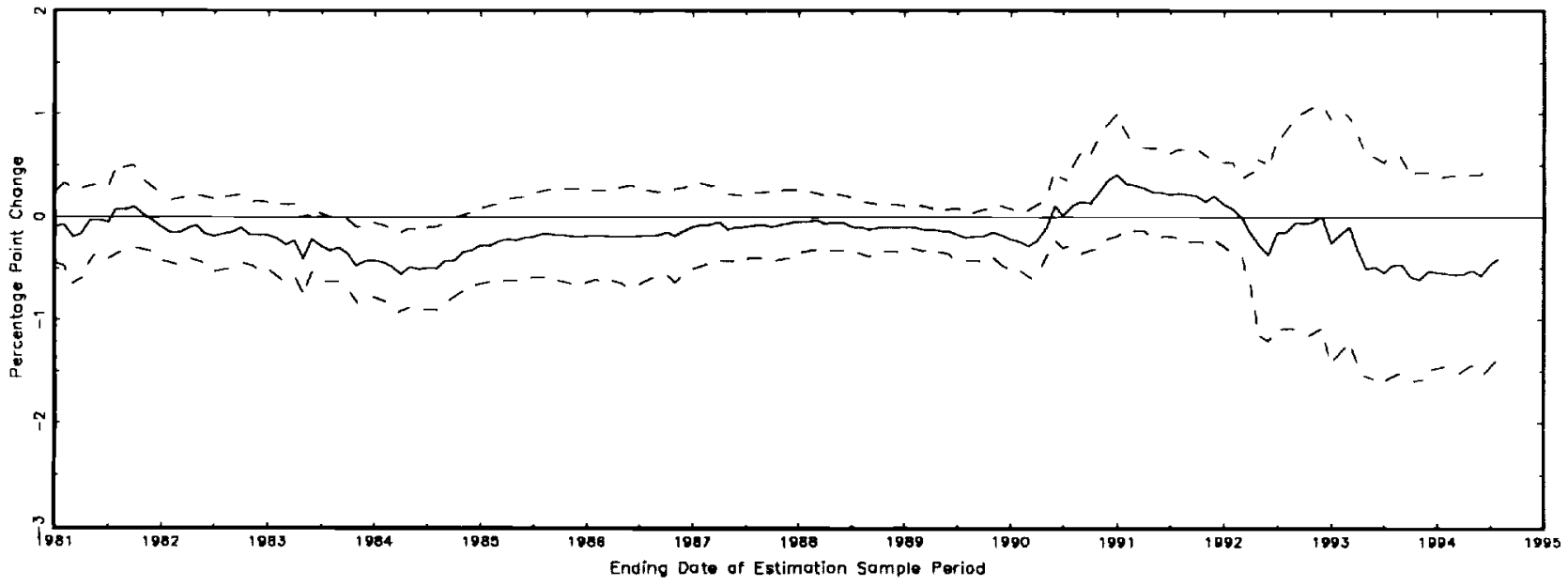

Response of Prices to Unit Federal Funds Rate Shock. 36 Month Harizon

Rolling Regressions using 10 year Samples

(with Two Stondord Doviatian Bands)

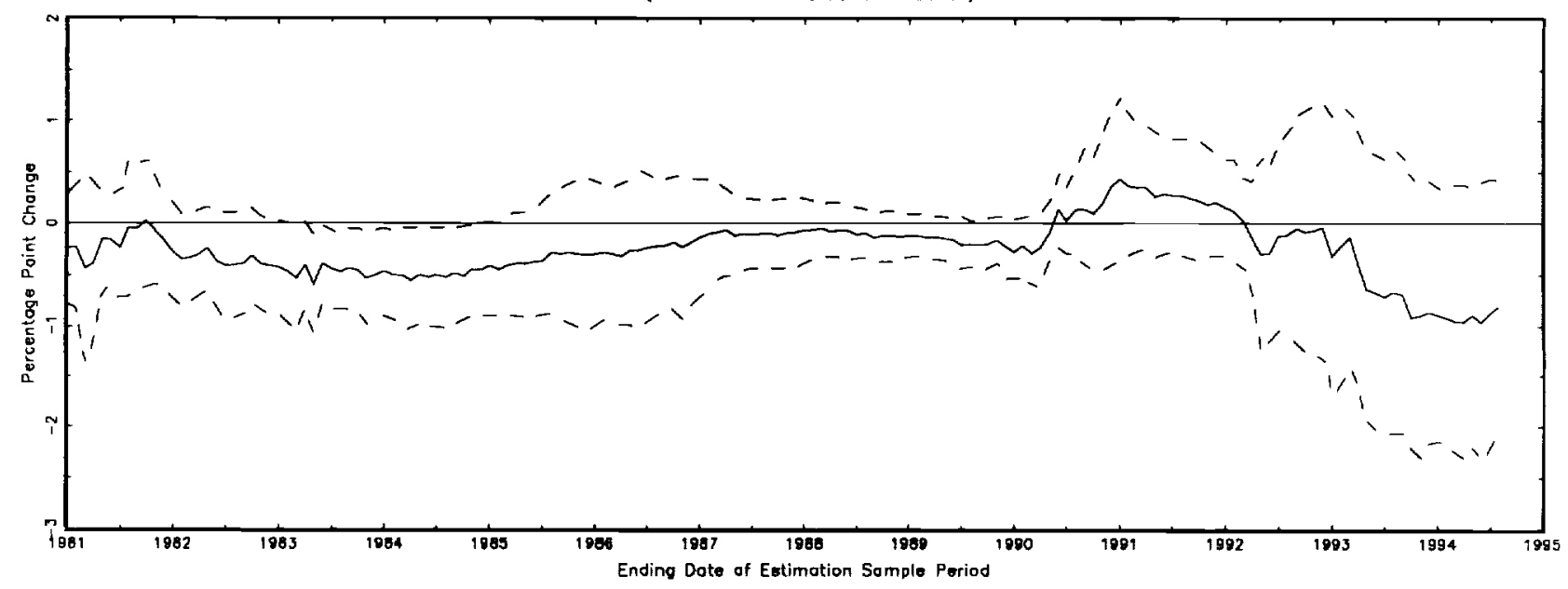


tion, the model (6), estimated over the sample from 1984:01 to 1994:07. Identification is achieve by assuming that VAR disturbances are related to the underlying economic shocks by a triangular (Choleski) decomposition of the covariance matrix of the reduced form errors. ${ }^{29}$ As described above, the monetary policy shock is identified by assuming that no variable other than the Federal Funds Rate responds to it contemporaneously. I label the portion of the reduced form error in the output equation orthogonal to this as the 'output' shock, the portion of error in the commodity price equation orthogonal to these two as the 'commodity price' shock, and the final part of the residual in the aggregate price equation that is orthogonal to all three of these as the 'aggregate price' shocks. Technically, the restriction is that $A(0)$ is lower triangular. This procedure, due originally to Sims (1980), has numerous shortcomings, but experimentation with an alternative suggested by Gali (1992) yields very similar results.

Figure 4 plots the impulse responses of output, commodity prices, aggregate prices and the Federal Funds Rate to 'output,' 'commodity price,' 'aggregate price,' and 'funds rate' shocks. ${ }^{30}$ Each response function is plotted with two-standard-deviation bands constructed using the delta method. Two points are worth noting. First, in all cases commodity prices (plotted in the second row) respond more quickly and in the same direction as aggregate prices (plotted in the third row). And second, for the three $\epsilon$ shocks, the response of output appears more precisely estimated than the response of aggregate prices. ${ }^{31}$

While they are somewhat interesting in and of themselves, the main use of these impulse responses is to construct policy rules given some objective function. To see how this is done, begin by noting that, for a given path of shocks, the first equation of the model (6) implies an estimated value for the aggregate price level of

$$
\hat{p}_{t}=\hat{A}_{11}(L) \epsilon_{p t}+\hat{A}_{12}(L) \epsilon_{c t}+\hat{A}_{13}(L) \epsilon_{y t}+\hat{A}_{14}(L) u_{t}
$$

\footnotetext{
${ }^{29}$ See Christiano, Eichenbaum and Evans (1994b) for a discussion of this identification procedure.

${ }^{30}$ These shocks have a very close correspondence to those that emerge from the Gali procedure, where they can be identified as a money supply shock, a raw material price shock, a general aggregate supply shock and a general aggregate demand shock.

${ }^{31}$ This is consistent with Cochrane's (1994) observation that real output is forecastable with high $R^{2}$ at horizons of several years.
} 
Figure 4: Impulse Response Functions for Four Variable VAR

(Estimated Response, with two standard deviation bands)

Output Rospomen to Dutpurt' Shock
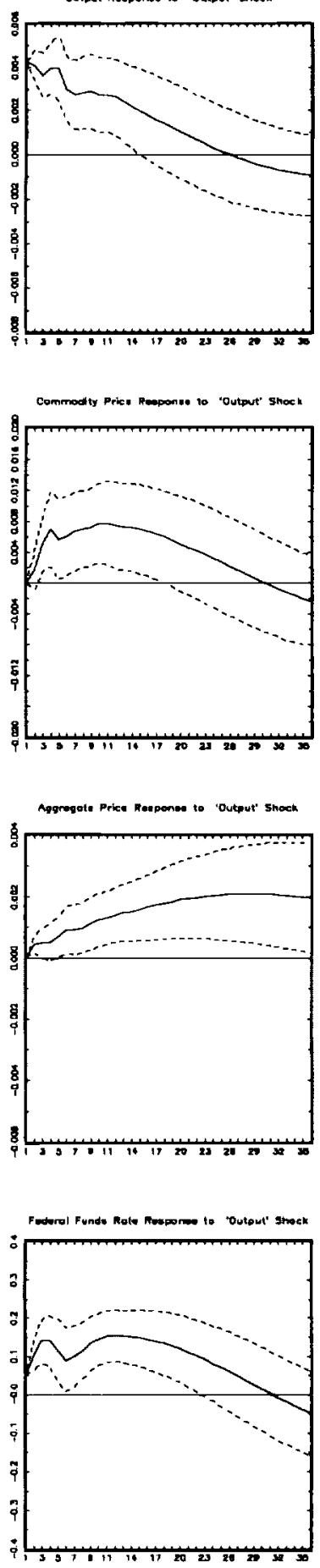

Outout Rovdonse to 'Commodtey PTise' shoek
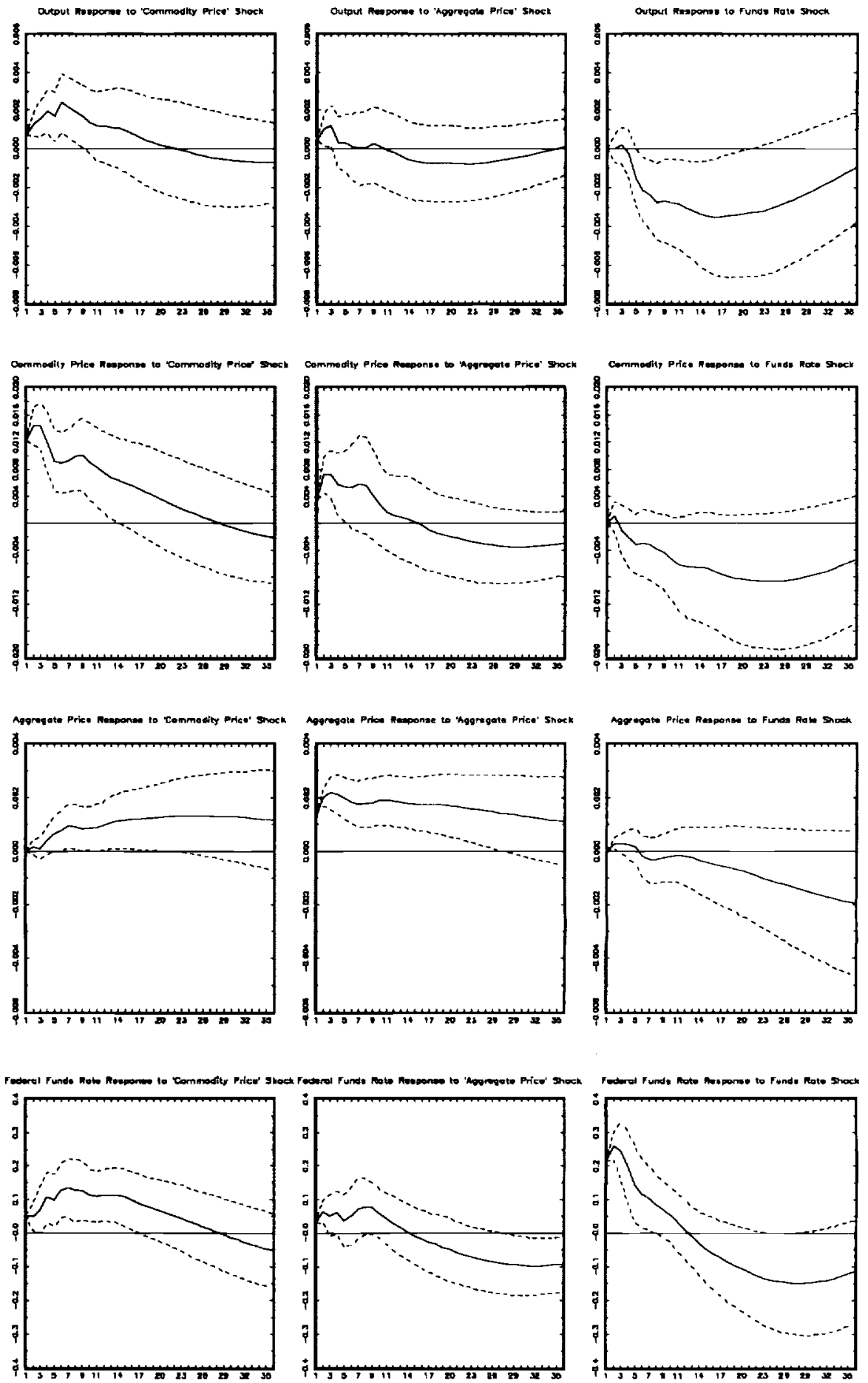
where the "n' denotes an estimated value. The $\hat{A}_{1 i}$ 's are the impulse response functions plotted in third row of Figure 4. In the context of the model (6), a policy rule is a sequence of $u_{t}$ 's given the realization of the $\epsilon$ 's, constructed to minimize a particular objective function.

One version of price level targeting is to choose a sequence of $u$ 's to minimize the average expected mean-square-error (MSE) of inflation over some future horizon:

$$
\min _{\left\{u_{i}\right\}} \frac{1}{h} \sum_{i=1}^{h} E\left(\hat{p}_{i}-p_{o}\right)^{2}
$$

where $p_{o}$ is the log of the base-period price level and $h$ is the policy makers horizon, the expectation is over the sampling distribution of $\hat{p}$, which is related to the covariance matrix of the estimated coefficients in equation (7). ${ }^{32}$ The $u$ 's are allowed to take the simple linear form

$$
\tilde{u}_{i}=\sum_{j=(p, c, y)} \sum_{k=0}^{\infty} \alpha_{j k} \epsilon_{j k}
$$

where the $\alpha_{i k}$ 's are constants that constitute the rule, and $\tilde{u}_{i}$ is the sequence of values that minimize the objective function (8). Taking account of the imprecision in the estimation of the impulse response functions, goes only part of the way toward addressing the problems described in the previous sections. A full treatment of uncertainty would require accounting for the frequency and size of structural breaks as well.

I examine results based on three policy objectives. The first, which might be termed passive, holds the Federal Funds Rate fixed in the face of the shock. ${ }^{33}$ The other two, which I will call active, minimize the average mean-square-error (MSE) of either the log of the price level or the log of nominal output over a thirty-six month horizon $(h=36) .{ }^{34}$ For each rule, I examine three experiments, one for each structural shock. In each of the nine resulting cases, $\epsilon_{j 0}=1$, and $\epsilon_{l k}=0$ for $l \neq j$ and

\footnotetext{
${ }^{32}$ In the implementation of this technique, a heteroskedasticity-robust covariance matrix of the coefficient estimates in the reduced-form VAR is used.

${ }^{33} \mathrm{As}$ is clear from the model, this is not a really a passive policy, as it involves shocks to overcome the estimated reaction function.

${ }^{34}$ Since the model is estimated in logs, the minimum MSE of nominal income policy minimized the MSE of the sum of the log of industrial production and the log of the CPI.
} 
$k \neq 0$. In other words, there is a unit innovation to one of the structural disturbances in the base period, and that is all. I then construct estimates for the sequences of $\left\{\alpha_{j k}\right\}$ for each $j$ individually.

Figure 5 reports the implied path of the Federal Funds Rate, aggregate prices and industrial production for each policy objective in response to each of the three structural shocks. The fixed Federal Funds Rate policy results in consistently higher output and prices than either of the other two polices. The activist policies both have the same profile regardless of the source of the shock. Output and price both rise initially, and then fall, with output falling more than prices.

Interestingly, both of the activist policies involve raising the funds rate immediately, and then lowering it slowly. This follows directly from the fact that prices respond slowly to policy innovations - see the third row of Figure 4. If the objective is to stabilize prices, then responses to exogenous shocks must come quickly in order to insure that future movements in prices are minimized. That is the argument for the Federal Reserve tightening immediately upon first sight of upward price pressure.

These calculations also have direct implications for the debate between advocates of price level targeting and those who favor targeting nominal GDP. To see why, I have computed the implied root-mean-square error for inflation and nominal income for each policy. For the price-targeting case, these are the square root of the minimize objective function (8).

The results are reported in Table 5. As a baseline, I include the calculation of the RMSE for a case labelled 'No Policy,' in which all of the $u_{i}$ 's are set to zero. (This is a 'policy' in which the authorities desist from introducing innovations into the Federal Funds Rate, and so it follows the path implied by the estimated reaction function.)

The computations suggest that nominal income targeting has a certain of robustness, as inclusion of real output in the objective function increases the RMSE for inflation only slightly. For the case of an output shock, the increase is from 0.90 to 1.09. But the move from price level targeting to nominal income targeting decreases the RMSE of nominal income substantially - from 3.01 to 1.89 when the output shock is the source of the instability. In other words, the inability to precisely estimate either the impact of shocks on prices, or the response of prices to policy 


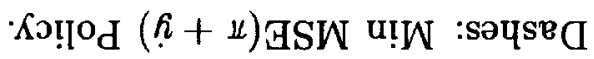

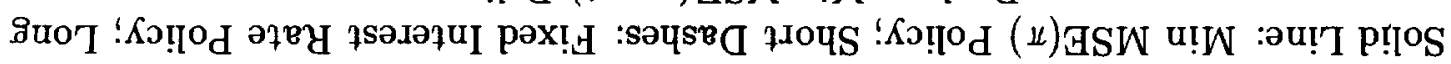

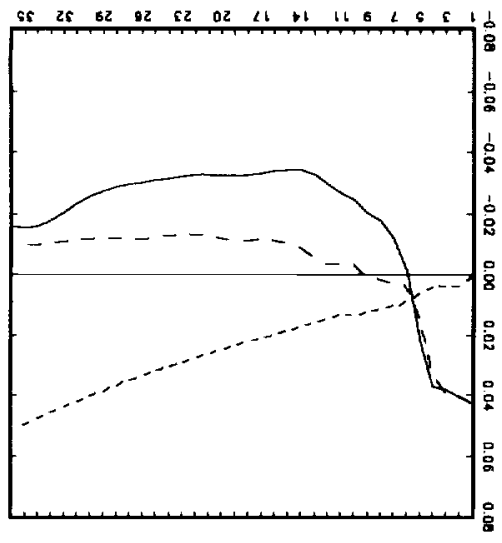

yous indino cosuadsoy indzno

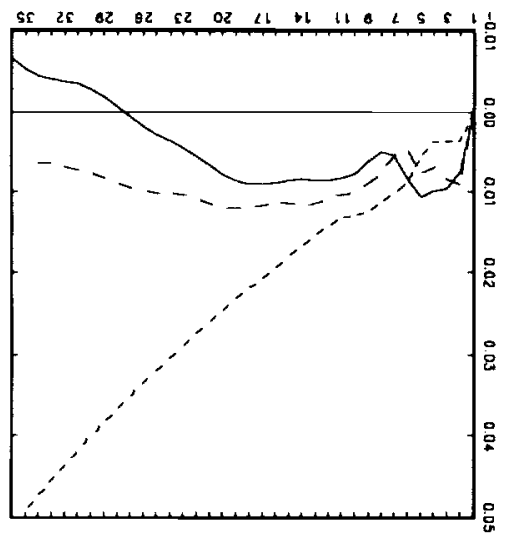

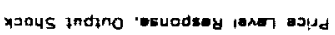

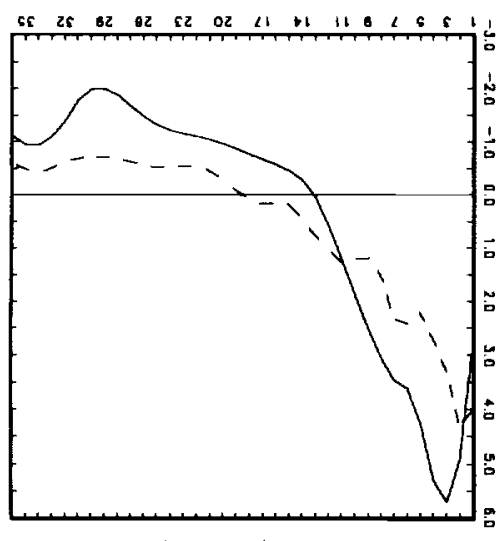

yoous indino -esuodeay ofoy spung

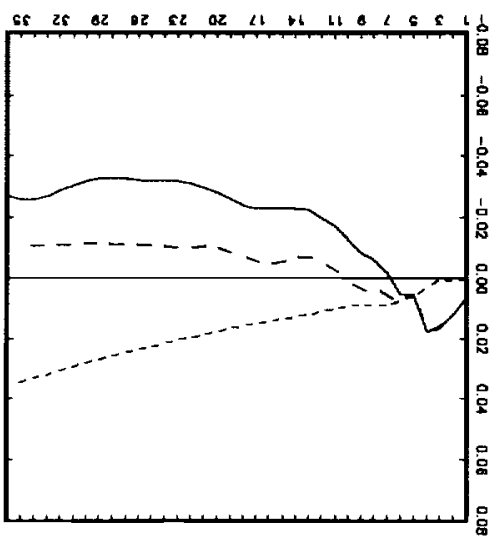

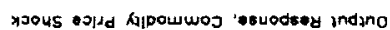

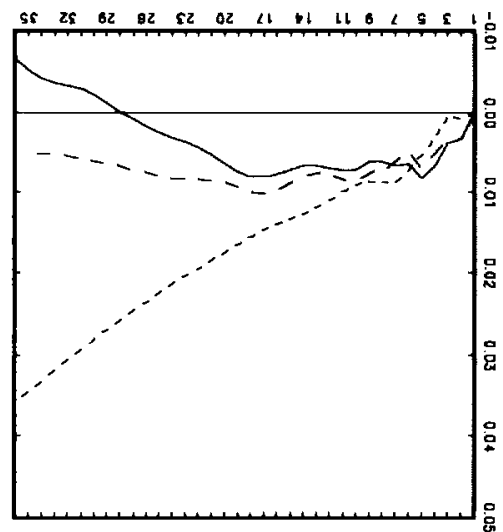

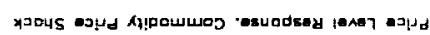

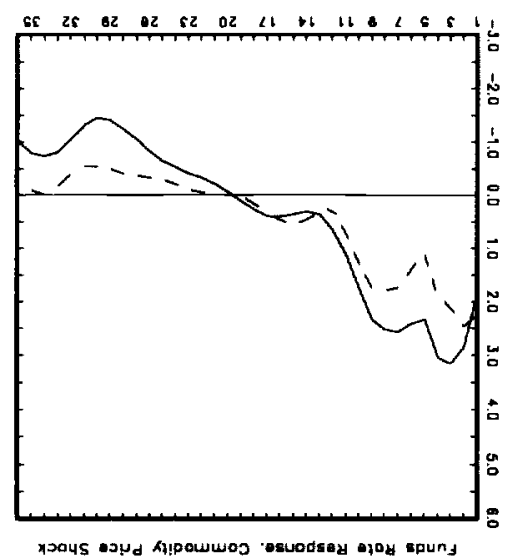

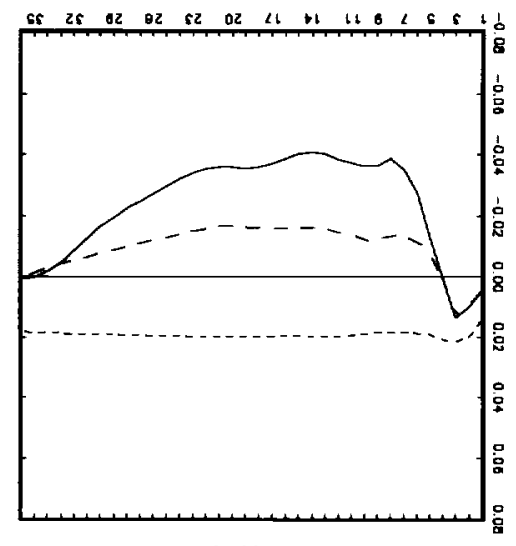

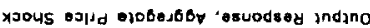

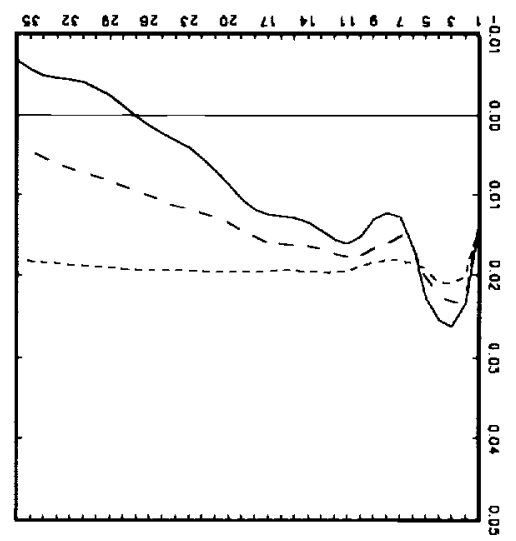

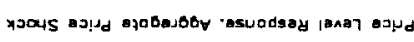

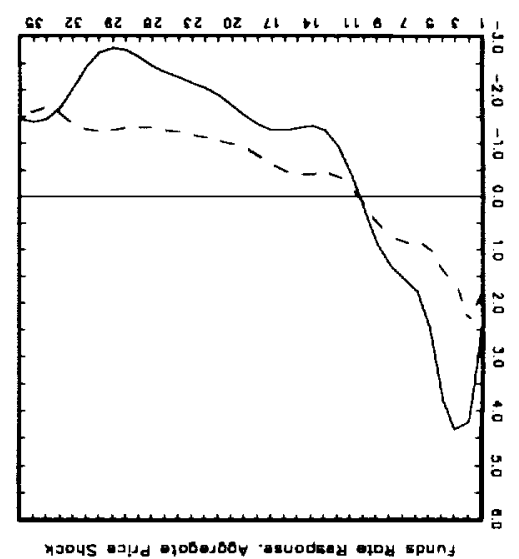

əsuods

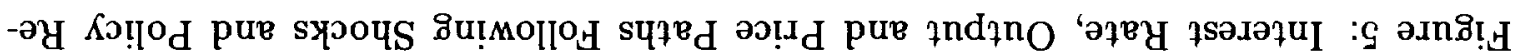


Table 5: Comparison of Policy Responses

\begin{tabular}{||l|c|c|c||}
\hline \hline \multicolumn{3}{||c||}{ Average RMSE of Inflation over 36 Month Horizon } \\
\hline \multirow{3}{*}{ Policy 'Rule' } & \multicolumn{3}{|c||}{ Source of Shock } \\
\cline { 2 - 4 } & $\begin{array}{c}\text { Aggregate } \\
\text { Price }\end{array}$ & $\begin{array}{c}\text { Commodity } \\
\text { Price }\end{array}$ & Output \\
\hline 'No Shocks' Policy & 1.75 & 1.20 & 1.66 \\
Fixed Interest Rate & 2.01 & 2.13 & 2.78 \\
Min MSE $(\pi+\dot{y})$ & 1.51 & 0.93 & 1.09 \\
Min MSE $(\pi)$ & 1.29 & 0.78 & 0.90 \\
\hline Average RMSE of Nominal Income over 36 Month Horizon \\
\hline \multicolumn{3}{|c||}{ Source of Shock } \\
Policy 'Rule' & \multicolumn{3}{|c||}{} \\
\cline { 2 - 4 } & Aggregate & Commodity & Output \\
\hline 'No Shocks' Policy & Price & Price & 3.25 \\
Fixed Interest Rate & 2.92 & 2.16 & 9.30 \\
Min MSE $(\pi+\dot{y})$ & 1.51 & 6.53 & 1.89 \\
Min MSE $(\pi)$ & 2.64 & 2.53 & 3.01 \\
\hline \hline
\end{tabular}

innovations, provides a strong argument for including real variables in the objective function.

Finally, one might ask how closely recent policy conforms to what would have been implied by either the price level or nominal income targeting rules plotted in Figure 5. A simulated interest rate path can be calculated by taking the estimated structural innovations, the $\hat{\epsilon}_{j t}$ 's, computing the optimal policy responses implied by equation (9), and then substituting the result into the equation for the Federal Funds Rate, which is the equivalent of equation (7). ${ }^{35}$

Figure 6 compares the actual path of the Federal Funds Rate with that implied by the estimated price level and nominal income targeting policies. Several findings emerge from examination of the figure. First, targeting the price level alone yields larger swings, as the funds rate reaches both higher and lower extremes. In addition,

\footnotetext{
${ }^{35}$ Performing the calculations in this way ignores a number of elements. In particular, there is no guarantee that the policy rules generated from the artificial experiment of one unit shock in one $\epsilon_{j k}$ at a time will be robust to sequences of shocks in all the $\epsilon_{j k}$ 's simultaneously. One clear reason for this is that it ignores the covariance of estimated coefficients both within and across the elements of the $\hat{A}_{i j}(L)$ 's.
} 
Figure 6: Comparison of Optimal and Actual Federal Funds Rate Paths

Monthly, 1987:06 to 1994:07

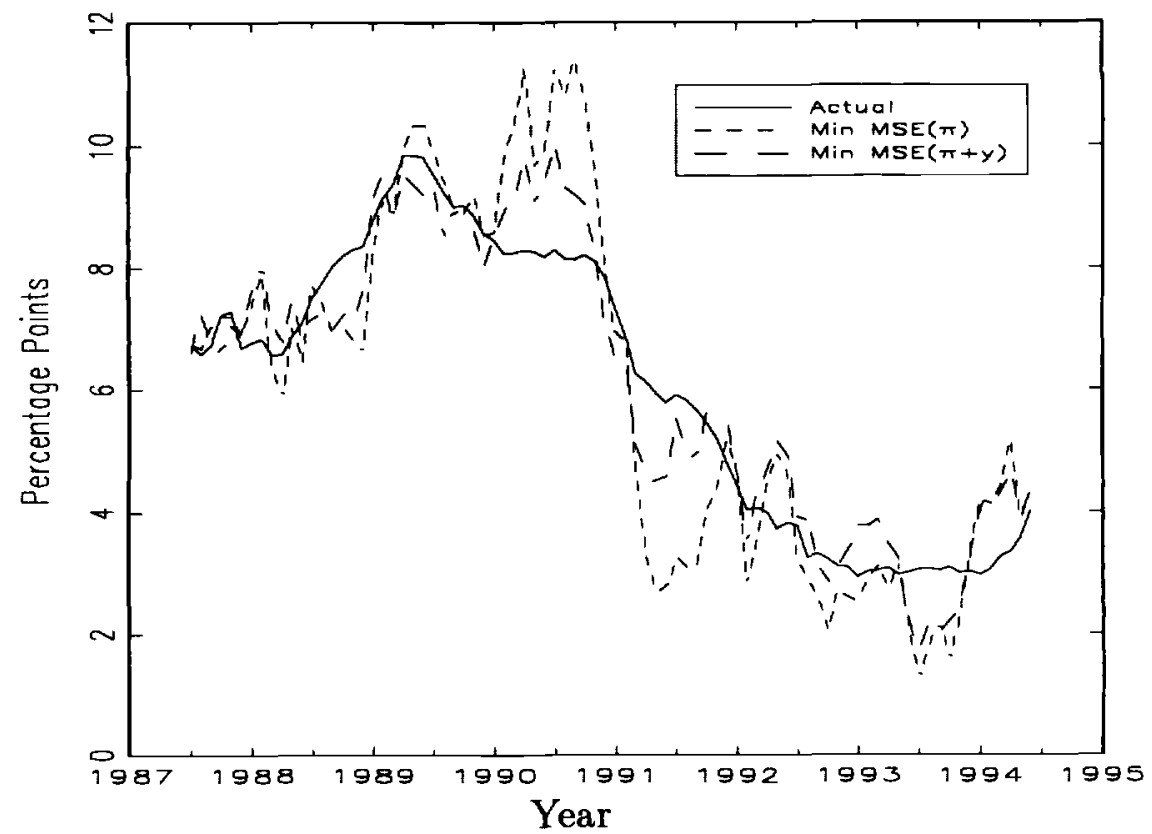

the actual funds rate is the least variable, looking like a smoothed version of the two simulated paths. But the general character of the plot suggests that the optimal policy response simply involves faster and bigger movements than those exhibited by the actual path. ${ }^{36}$

\section{Conclusion}

Empirical analysis of the inflation process leads to a number of conclusions relevant for current policy formulation. First, inflation is extremely difficult to forecast. Even at short horizons of three months, and for a sample including only the last ten years, the root-mean-square error of inflation forecasts is always above one-percentage point (at an annual rate).

Second, the relationship between potential inflation indicators and inflation is

\footnotetext{
${ }^{36}$ As one would expect, these large policy innovations result in less stable real output, highlighting that the ultimate issue in policy making is still the relative weight on prices and output in the objective function.
} 
suspect as a basis for policy. This is true both because whether a indicator fits well in-sample says virtually nothing about its performance out-of-sample, and as a result of the fact that the relationship between inflation and inflation indicators is extremely unstable, shifting systematically when monetary policy operating procedures change.

The third major conclusion of the paper is that the relationship between monetary policy instruments, such as the Federal Funds Rate, and inflation varies substantially over time and cannot be estimated precisely. The point-estimate of the response of prices to innovations in the Federal Funds Rate changes sign over time, and is rarely significantly different from zero.

But policy makers must make decisions on a day-to-day basis, and so stopping here is not terribly useful. Instead, one can take these lessons to heart, and construct policy rules that incorporate the imprecision inherent in inflation forecasts and policy responses. These have the following implications. Since prices take time to respond to all types of impulses, the objective of price stability implies raising the Federal Funds Rate immediately following a shock, rather than waiting for prices to rise before acting. Furthermore, comparison of the results of price level targeting with nominal income targeting suggests that the difficulties inherent in forecasting and controlling the former provide an argument for focusing on the latter. 


\section{Data Appendix}

This appendix lists all of the data used in the paper. When the data are from CITIBASE, the pnuemonics are in parentheses at the end of the descriptions. All data are available seasonally adjusted from at least 1967:01 to the present. The one exception is exception of the average hourly earnings index, which is not seasonally adjusted, and was adjusted by using deterministic seasonal dummy variables.

1. Prices: CPI-X1 from 1967:01 to 1982:12, spliced to the All Items CPI-U (PUNEW).

2. Industrial Production: Total Index (IP).

3. Average Hourly Earnings: LEMXO Average Hourly Earnings of Production Workers, excluding overtime (LEMXO).

4. Journal of Commerce Spot Price Index: Industrial Material Price Index, 18 Commodities (FCJM).

5. NAPM Spot Index: National Association of Purchasing Managers Spot Price Index, All Commodities (PSCCOM).

6. Capacity Utilization: Manufacturing, Total (IPXMCA).

7. Unemployment Rate: All Workers, 16 Years and over (LHUR).

8. Monetary Base: Adjusted for Reserve Requirement Changes (FRB St. Louis) (FMBASE).

9. M1: Money Stock, currency, travelers checks, demand deposits and other checkable deposits (FM1).

10. M2: Money Stock, M1 plus overnight repurchase agreements, Eurodollars, etc. (FM2).

11. Federal Funds Rate (FYFF)

12. 10 Year Bond Rate: U.S. Treasury Constant Maturities,10-YR. (FYGT10).

13. Weekly Hours Index: Total, Private Nonagricultural (LWHX)

14. Trade Weighted Value of the Dollar: Webb and Rowe.

15. NAPM Diffusion Index: Neimera.

16. Price of Gold, London fix: Webb and Rowe.

17. Price of Oil, Brent North Sea Crude: Webb and Rowe.

18. Commercial Paper Rate: Interest Rate, Commercial Paper, 6-Month (FYCP). 
19. Nominal GDP: Gross Domestic Product, Current Dollars (GDP).

20. Nonborrowed Reserves: depository institutions reserves, nonborrowed plus extended credit, adjusted for reserve requirement changes (FMRNBC). 


\section{References}

Andrews, Donald W.K., 'Tests for Parameter Instability and Structural Change with Unknown Change Point,' Econometrica 61 (July 1993) 821-856.

and Werner Ploberger, 'Optimal Tests When a Nuisance Parameter is Present Only Under the Alternative,' Econometrica 62 (November 1994) 1383-1414.

Ball, Laurence and Stephen G. Cecchetti 'Inflation and Uncertainty at Short and Long Horizons,' Brookings Papers on Economic Activity 1990:1, 215-245.

and , 'Imperfect Information and Staggered Price Setting,' American Economic Review 78 (December 1988) 999-1018.

Brainard, William C., 'Uncertainty and the Effectiveness of Policy,'American Economic Review 57 (May 1967) 411-425.

Bryan, Michael F. and Stephen G. Cecchetti, 'Measuring Core Inflation,' in Monetary Policy, N. Gregory Mankiw, ed., Chicago: University of Chicago Press for NBER, 1994, 195-215.

Caskey, John, 'Modeling the Formation of Price Expectations: A Bayesian Approach,' American Economic Review 75 (September 1985) 768-777.

Christiano, Lawrence J., Martin Eichenbaum and Charles L. Evans, 'The Effects of Monetary Policy Shocks: Evidence from the Flow of Funds,' Federal Reserve Bank of Chicago Working Paper 94-2, March 1994, a.

and __ 'Identification and the Effects of Monetary Policy Shocks,'

Federal Reserve Bank of Chicago Working Paper 94-2, May 1994, $\underline{\text { b. }}$

Cochrane, John H., 'Shocks,' Carnegie-Rochester Conference Series on Public Policy, vol. 41, December 1994.

Duca, John V., 'The Case of the Missing M2' Federal Reserve Bank of Dallas Economic Review, 2nd Quarter 1992, 1-24.

Evans, Martin D.D. and Paul Wachtel, " Journal of Money, Credit and Banking 25 (August 1993, Part 2) 475-511.

Feldstein, Martin and James H. Stock, 'The Use of Monetary Aggregates to Target Nominal GDP,' in Monetary Policy, N. Gregory Mankiw, ed., Chicago: University of Chicago Press for NBER, 1994, 7-70.

Fisher, Mark E. and Seater, John J., 'Long-Run Neutrality and Superneutrality in an ARIMA Framework,' American Economic Review 83(June 1993) 402-15.

Galí, Jordi, 'How Well Does the IS-LM Model Fit Postwar U.S. Data?' Quarterly Journal of Economics 107 (May 1992) 709-738.

Hallman, Jeffrey J., Richard D. Porter and David H. Small, 'Is the Price Level Tied to the M2 Monetary Aggregate in the Long Run?' American-Economic-Review 81(4), September 1991, 841-58. 
Hansen, Bruce E. 'Approximate Asymptotic P-Values for Structure Change Tests,' mimeo., Department of Economics, Boston College, April 1995.

Kareken, John H. and Robert M. Solow, 'Lags in Monetary Policy,' in Commission on Money and Credit, Stabilization Policies, 1963, 14-96.

Lucas, Robert E., Jr. 'Econometric Policy Evaluation: A Critique,' Carnegie-Rochester Conference Series on Public Policy, No. 2, 19-46. ,'Money Demand in the United States: A Quantitative Review' Carnegie Rochester Conference Series on Public Policy 29, (Autumn 1988) 137-67.

Miyao, Ryuzo. Essays on Money and Output. Unpublished Ph.D. Dissertation, Department of Economics, Harvard University, August 1994.

Newey, Whitney K. and Kenneth D. West, 'A Simple, Positive Definite, Heteroskedasticity and Autocorrelation Consistent Covariance Matrix,'Econometrica 55, May 1987, 703-708.

Niemira, Michael P. and Philip A. Klein. Forecasting Financial and Economic Cycles. New York: John Wiley and Sons, Inc., 1994.

Quandt, Richard E. 'Tests of the Hypothesis that a Linear Regression System Obeys Two Separate Regimes,' Journal of the American Statistical Association 55 (1960) 324-330.

Sims, Christopher A., 'Money, Income, and Causality' American-Economic-Review 62 (September 1972) 540-52.

, 'Macroeconomics and Reality,' Econometrica 48 (January 1980) 1-48.

, 'Interpreting the Macroeconomic Time Series Facts: The Effects of Monetary Policy,' European Economic Review 36: (1992) 975-1000.

Stock, James H. and Mark W. Watson, 'A Simple Estimator of Cointegrating Vectors in Higher Order Integrated Systems,' Econometrica 61 (July 1993) 783-820. and $\_$,Evidence on Structural Instability in Macroeconomic Time Series Relations,' mimeo., Kennedy School of Government, Harvard University, July 1994.

Strongin, Steven, 'The Identification of Monetary Policy Disturbances: Explaining the Liquidity Puzzle,' Federal Reserve Bank of Chicago Working Paper 92-27, November 1992 .

Webb, Roy H. and Tazewell S. Rowe, 'An Index of Leading Indicators for Inflation,' mimeo., Research Department, Federal Reserve Bank of Richmond, 1994.

Woodford, Michael, 'Nonstandard Indicators for Monetary Policy: Can Their Usefulness Be Judged from Forecasting Regressions?,' in Monetary Policy, N. Gregory Mankiw, ed., Chicago: University of Chicago Press for NBER, 1994, 95-115. 